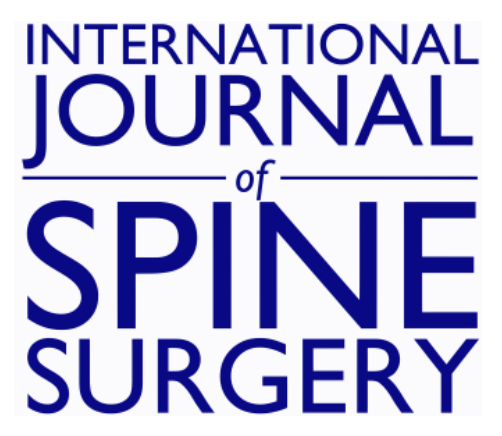

\title{
The Influence of Sex on Clinical Outcomes in Minimally Invasive Lumbar Decompression
}

Michael T. Nolte, Nathaniel W. Jenkins, James M. Parrish, Shruthi Mohan, Cara E. Geoghegan, Caroline N. Jadczak, Nadia M. Hrynewycz and Kern Singh

Int J Spine Surg 2021, 15 (4) 763-769

doi: https://doi.org/10.14444/8098

http://ijssurgery.com/content/15/4/763

This information is current as of April 26, 2023.

Email Alerts Receive free email-alerts when new articles cite this article. Sign up at: http://ijssurgery.com/alerts 


\title{
The Influence of Sex on Clinical Outcomes in Minimally Invasive Lumbar Decompression
}

\author{
MICHAEL T. NOLTE, MD, NATHANIEL W. JENKINS, MS, JAMES M. PARRISH, MPH, \\ SHRUTHI MOHAN, BS, CARA E. GEOGHEGAN, BS, CAROLINE N. JADCZAK, BS, \\ NADIA M. HRYNEWYCZ, BS, KERN SINGH, MD \\ Department of Orthopaedic Surgery, Rush University Medical Center, Chicago, Illinois
}

\begin{abstract}
Background: Research focused on postoperative outcomes among men and women undergoing minimally invasive lumbar decompression (MIS LD) spine surgery is sparse. This study aims to assess the influence of sex on postoperative patient-reported outcome measure (PROM) evaluations and achievement of a minimum clinically important difference (MCID).

Methods: A prospectively maintained surgical database was retrospectively queried for patients undergoing primary or revision, single or multilevel LD procedures from 2011 to 2019. Patients with incomplete visual analog scale (VAS) leg or back surveys were excluded. Demographic and operative variables were recorded, and a chi-squared analysis or $t$ tests were used to compare by sex. PROMs were evaluated from preoperative to postoperative time points. PROM score differences and postoperative improvement were evaluated between sexes by a $t$ test. Achievement of MCID by sex was compared using chi-squared analysis.

Results: The study cohort $(n=572)$ was $70 \%$ male $(n=398)$, had an average age of 47 years, and $42 \%$ were obese. Sexes differed in preoperative VAS leg, Oswestry Disability Index (ODI), and 12-item short form (SF-12)-physical composite score (PCS) scores (all $P<.05)$ and in ODI at 6 and 12 weeks $(P=.048 ; P=.001)$ and VAS back and leg scores at 6 months $(P=.039 ; P=.019)$. Both sexes significantly improved $(P<.050)$ all PROMs at all time points except for VAS back at 1 year for women and ODI at 6 weeks and 6 months for men. The only significant difference in achievement of MCID was for ODI at 6 months $(P=.008)$.

Conclusions: Significant preoperative differences were observed among sexes with ODI, SF-12-PCS, and VAS leg scores. By 1 year, there were no significant sex differences for any PROM or for achievement of MCID. MIS LD has an equivalent role for both sexes in achieving MCID.

Level of Evidence: 3.

Clinical Relevance: Results demonstrate no sex difference in PROMs following LD.
\end{abstract}

Lumbar Spine

Keywords: LD, lumbar decompression, sex, MCID, minimum clinically important difference

\section{INTRODUCTION}

Degenerative pathology of the lumbar spine in the general adult population is incredibly common. ${ }^{1,2}$ An estimated 10 to $20 \%$ of adults, for example, will experience symptomatic lumbar spinal stenosis during their lifetimes. ${ }^{3}$ Decompressive surgery is the gold standard treatment for pathologies, such as herniated nucleus pulposus and stenosis that have not responded to conservative treatment. ${ }^{4,5}$ Furthermore, lumbar decompression surgery is the most commonly performed procedure by spine surgeons annually. ${ }^{6}$ Although the indications for surgery and surgical technique are similar, some groups have demonstrated different degrees of improvement in patient-reported outcome measures
(PROMs) in response to surgery. ${ }^{7,8}$ Given the frequency of the procedure and the demographic variability of this patient population, there has been much interest in discerning the relationship between these demographic factors and perioperative PROMs.

Sex is one demographic factor that has been proposed to play an important role in pathology, symptomatology, and response to treatment for degenerative pathology of the lumbar spine. ${ }^{9-11}$ While some research has suggested that men and women fare differently in response to surgery, ${ }^{11,12}$ other research has suggested there are no major differences. ${ }^{13,14}$ However, prior studies have either analyzed lumbar surgeries other than decompres- 
$\operatorname{sion}^{12,14}$ or have assessed for statistical rather than clinical divergence between sexes. ${ }^{15-17}$

Further research is necessary to grasp the true clinical impact of sex on perioperative outcomes for lumbar spine decompression surgery. Analysis of the minimum clinically important difference (MCID) in PROMs may provide greater clinical context to the numeric scales of widely used outcome measures. Surgeons can use these clinical findings to counsel their patients, set expectations, and provide more realistic data to healthcare payers. Thus, the aim of the present study was to elucidate the relationship between sex and the likelihood of achievement of MCID for several of the most commonly used PROMs in spine surgery today. ${ }^{18}$

\section{METHODS}

\section{Patient Selection}

Institutional review board approval (ORA 14051301) was granted for a prospective surgical registry of spine surgery patients under the care of one surgeon at a single institution. This registry was retrospectively reviewed from December 2011 to July 2019 for patients who underwent lumbar decompressions. Included patients were required to have undergone primary or revision, single or multilevel lumbar decompressions. Patients were excluded from the study if they did not complete the preoperative visual analog scale (VAS) back or VAS leg surveys.

\section{Data Collection}

Patient records were reviewed for preoperative demographic variables, including age, sex, disease burden as evaluated by the Charlson Comorbidity Index, American Society of Anesthesiology score, tobacco use, and preoperative medical and spinal pathology diagnosis. Evaluated operative variables included the number of vertebral levels decompressed, operative time, estimated blood loss, duration of inpatient stay following surgery, and day of discharge. PROMs were evaluated at preand postoperative time points (eg, 6 weeks, 12 weeks, 6 months, and 1 year). Administered surveys included VAS back, VAS leg, and Oswestry Disability Index (ODI), 12-item short form (SF12)-physical composite score (PCS), and PatientReported Outcomes Measurement Information System (PROMIS) Physical Function (PF).

\section{Statistical Analysis}

Demographic and operative variables were evaluated for differences among male and female sex subgroups using a chi-squared or Student $t$ test where appropriate. A $t$ test analyzed PROM score differences among sexes, while a paired $t$ test evaluated postoperative improvement within each subgroup. A chi-squared test compared sex proportions that achieved MCID following lumbar decompression. MCID values were used based on previous literature values for VAS back (2.2), ${ }^{19}$ VAS leg (5.0 ), ${ }^{19}$ ODI (8.2 ), ${ }^{19}$ SF-12-PCS (2.5), ${ }^{19}$ and PROMIS PF (4.5). ${ }^{20}$ Statistical analysis was performed using Stata SE 16.1 (College Station, Texas), and statistical significance was set at $\alpha=.05$.

\section{RESULTS}

\section{Study Cohort}

In total, 572 eligible patients underwent lumbar decompression. The male to female ratio was $69.6 \%$ to $30.4 \%$, respectively (Table 1 ). The average age was 46.8 years, and $42 \%$ of the cohort was obese (body mass index $\geq 30$ ). The only significant differences among sexes were a greater proportion of male smokers than female smokers $(16.4 \%$ versus $8.6 \% ; P=.014)$, and females had a greater rate of arthritis $(13.2 \%$ versus $6.3 \% ; P=.006)$. The most common preoperative medical diagnoses was hypertension $(23.7 \%)$, and the mean Charlson Comorbidity Index score was $1.4 \pm 1.7$. The three most common spinal pathologies were herniated nucleus pulposus $(76.2 \%)$, central stenosis $(71.3 \%)$, and foraminal stenosis $(44.4 \%)$.

\section{Operative Characteristics}

There were no significant differences in the evaluated operative variable among sexes (Table 2). The majority of procedures decompressed a single level $(78.3 \%)$. The mean operative time was $46.6 \pm 17.7$ minutes, and mean estimated blood loss was $28.6 \mathrm{~mL}$. The mean postoperative hospital stay was 29.9 hours, with the majority of patients being discharged on postoperative day zero $(61.7 \%)$.

\section{Patient-Reported Outcomes}

At all time points, there were no significant differences among sexes for PROMIS PF (Table 3). Preoperative mean PROM score differences between sexes were observed for VAS leg $(P=.019)$, ODI $(P=$ 
Table 1. Patient demographics and baseline characteristics by sex.

\begin{tabular}{|c|c|c|c|c|}
\hline & Total, \% (n) & Female, $\%(n)$ & Male, \% (n) & $P$ Value \\
\hline Participants & $100.0(572)$ & 30.4 (174) & $69.6(398)$ & \\
\hline Age, mean $\pm \mathrm{SD}, \mathrm{y}$ & $46.8 \pm 14.3$ & $48.6 \pm 13.4$ & $46.0 \pm 14.6$ & .051 \\
\hline $\mathrm{BMI}, \mathrm{k} / \mathrm{m}^{2}$ & & & & .461 \\
\hline Not obese $($ BMI < 30) & $58.0(332)$ & $60.3(105)$ & $57.0(227)$ & \\
\hline Obese $(\mathrm{BMI} \geq 30)$ & $42.0(240)$ & $39.7(69)$ & $43.0(171)$ & \\
\hline Smoking status & & & & .014 \\
\hline Nonsmoker & $86.0(490)$ & $91.4(159)$ & $83.6(331)$ & \\
\hline Smoker & $14.0(80)$ & $8.6(15)$ & $16.4(65)$ & \\
\hline $\mathrm{CCI}$, mean $\pm \mathrm{SD}$ & $1.4 \pm 1.7$ & $1.4 \pm 1.6$ & $1.4 \pm 1.7$ & .973 \\
\hline ASA score & & & & .204 \\
\hline 1 & $35.5(164)$ & $29.6(40)$ & $37.9(124)$ & \\
\hline 2 & $51.1(236)$ & $58.5(79)$ & $48.0(157)$ & \\
\hline$>3$ & $13.4(62)$ & $11.9(16)$ & $14.1(46)$ & \\
\hline \multicolumn{5}{|l|}{ Preoperative medical diagnoses ${ }^{\mathrm{b}}$} \\
\hline Myocardial infarction & $2.5(14)$ & $0.6(1)$ & $3.3(13)$ & .054 \\
\hline AIDS & $0.2(1)$ & $0.0(0)$ & $0.3(1)$ & .507 \\
\hline Uncomplicated diabetes & $5.8(33)$ & $5.2(9)$ & $6.1(24)$ & .676 \\
\hline Complicated diabetes & $0.4(2)$ & $0.0(0)$ & $0.5(2)$ & .348 \\
\hline Congestive heart failure & $0.4(2)$ & $0.6(1)$ & $0.3(1)$ & .549 \\
\hline Hypertension & $23.7(135)$ & $20.7(36)$ & $25.0(99)$ & .265 \\
\hline Neurologic disease & $0.2(1)$ & $0.0(0)$ & $0.3(1)$ & .507 \\
\hline Arthritis & $8.4(48)$ & $13.2(23)$ & $6.3(25)$ & .006 \\
\hline Renal failure & $0.4(2)$ & $0.6(1)$ & $0.3(1)$ & .549 \\
\hline Metastasis & $0.5(3)$ & $0.6(1)$ & $0.5(2)$ & .916 \\
\hline Peripheral vascular disease & $1.1(6)$ & $0.6(1)$ & $1.3(5)$ & .459 \\
\hline \multicolumn{5}{|l|}{ Preoperative spinal pathology } \\
\hline Spondylolisthesis & $4.4(25)$ & $6.3(11)$ & $3.5(14)$ & .131 \\
\hline Isthmic spondylolisthesis & $2.4(8)$ & $4.0(4)$ & $1.8(4)$ & .225 \\
\hline Retro-listhesis & $0.4(2)$ & $0.6(1)$ & $0.3(1)$ & .548 \\
\hline Lateral listhesis & $0.2(1)$ & $0.0(0)$ & $0.3(1)$ & .508 \\
\hline Herniated nucleus pulposus & $76.2(436)$ & $73.6(128)$ & $77.4(308)$ & .791 \\
\hline Degenerative disc disease & $2.3(13)$ & $3.5(6)$ & $1.8(7)$ & .212 \\
\hline Central/spinal stenosis & $71.3(408)$ & $70.1(122)$ & $71.9(286)$ & .671 \\
\hline Foraminal stenosis & $44.4(254)$ & $43.1(75)$ & 45.0 (179) & .679 \\
\hline
\end{tabular}

Abbreviations: AIDS, acquired immunodeficiency syndrome; ASA, American Society of Anesthesiology; BMI, body mass index; CCI, Charlson Comorbidity Index; SD, standard deviation.

${ }^{\text {a }} P$ value was calculated using the Student $t$ test (continuous), chi-square (categorical), or the Fisher exact test (categorical).

${ }^{\mathrm{b}}$ There were no patients in our study with a recorded medical history of paraplegia or liver disease.

A bolded $\mathrm{P}$ value $(<0.05)$ indicates a statistically significant difference between the two groups being compared.

$.001)$, and SF-12-PCS $(P=.025)$. Postoperative mean differences between sexes were observed for VAS back at 6 months $(P=.039)$, VAS leg at 6 months $(P$ $=.018)$, and ODI scores at 6 and 12 weeks $(P=.048$; $P=.001)$. Statistically significant improvements $(P<$ $.05)$ were observed for all PROMs at all time points with the exception of VAS back at 1 year for women and ODI at 6 weeks and 6 months for men. There were no significant sex differences in achieving MCID for pain (VAS back, VAS leg) and physical function (SF-12-PCS, PROMIS PF) metrics at all time points (Table 4). At 6 months, there was a

Table 2. Operative characteristics by sex.

\begin{tabular}{|c|c|c|c|c|}
\hline & Total, \% (n) & Female, \% (n) & Male, $\%$ (n) & $P$ Value $^{\mathrm{a}}$ \\
\hline Number of operative levels & & & & .888 \\
\hline 1-level & $78.3(448)$ & $79.3(138)$ & $77.9(310)$ & \\
\hline 2-level & $18.2(104)$ & $17.8(31)$ & $18.3(73)$ & \\
\hline 3-level & $3.3(19)$ & $2.9(5)$ & $3.5(14)$ & \\
\hline 4-level & $0.2(1)$ & $0.0(0)$ & $0.3(1)$ & \\
\hline Operative time $^{\mathrm{b}}$, mean $\pm \mathrm{SD}$, min & $46.6 \pm 17.7$ & $45.9 \pm 16.3$ & $46.9 \pm 18.3$ & .538 \\
\hline Estimated blood loss, mean $\pm \mathrm{SD}, \mathrm{mL}$ & $28.6 \pm 34.0$ & $26.8 \pm 6.4$ & $29.4 \pm 40.5$ & .401 \\
\hline Length of hospital stay, mean $\pm \mathrm{SD}, \mathrm{h}$ & $29.9 \pm 5.8$ & $29.2 \pm 5.5$ & $31.3 \pm 6.3$ & .055 \\
\hline Day of discharge & & & & .966 \\
\hline POD 0 & $61.7(340)$ & $60.8(104)$ & $62.1(236)$ & \\
\hline POD 1 & $7.3(40)$ & $7.6(13)$ & $7.1(27)$ & \\
\hline POD 2 & $0.9(5)$ & $1.2(2)$ & $0.8(3)$ & \\
\hline $\mathrm{POD} \geq 3$ & $0.9(5)$ & $1.2(2)$ & 0.8 (3) & \\
\hline
\end{tabular}

Abbreviations: POD, postoperative day; SD, standard deviation.

${ }^{a} P$ value was calculated using the Student $t$ test (continuous), chi-square analysis (categorical), or the Fisher exact test (categorical).

${ }^{\mathrm{b}}$ Operative time was measured from skin incision to skin closure. 
Table 3. Patient reported outcome comparison by sex.

\begin{tabular}{|c|c|c|c|c|c|}
\hline & \multicolumn{2}{|c|}{ Female } & \multicolumn{2}{|c|}{ Male } & \multirow[b]{2}{*}{$P$ value $^{\mathrm{b}}$} \\
\hline & Mean \pm SD $(n)$ & $P$ Value $^{\text {a }}$ & Mean \pm SD $(n)$ & $P$ Value $^{\mathrm{a}}$ & \\
\hline \multicolumn{6}{|l|}{ VAS back } \\
\hline Preoperative & $6.0 \pm 2.6(135)$ & & $6.1 \pm 2.6(298)$ & & .937 \\
\hline 6 week & $2.7 \pm 3.0(135)$ & $<.001$ & $3.0 \pm 3.1(298)$ & $<.001$ & .273 \\
\hline 12 week & $3.1 \pm 3.2(79)$ & $<.001$ & $3.3 \pm 3.1(183)$ & $<.001$ & .527 \\
\hline 6 month & $3.0 \pm 3.1(65)$ & $<.001$ & $4.0 \pm 3.1(131)$ & $<.001$ & .039 \\
\hline 1 year & $3.4 \pm 2.8(45)$ & .053 & $3.4 \pm 3.2(81)$ & .003 & .980 \\
\hline \multicolumn{6}{|l|}{ VAS leg } \\
\hline Preoperative & $6.4 \pm 2.6(135)$ & & $6.1 \pm 2.5(298)$ & & .019 \\
\hline 6 week & $2.9 \pm 3.5(135)$ & $<.001$ & $2.9 \pm 3.2(298)$ & $<.001$ & .864 \\
\hline 12 week & $3.4 \pm 3.9(79)$ & $<.001$ & $2.8 \pm 3.4(184)$ & $<.001$ & .184 \\
\hline 6 month & $2.6 \pm 3.4(64)$ & $<.001$ & $3.6 \pm 3.4(130)$ & $<.001$ & .019 \\
\hline 1 year & $2.8 \pm 3.5(45)$ & $<.001$ & $2.9 \pm 3.3(81)$ & $<.001$ & .723 \\
\hline \multicolumn{6}{|l|}{ ODI } \\
\hline Preoperative & $45.8 \pm 17.7(135)$ & & $41.9 \pm 18.1(299)$ & & .001 \\
\hline 6 week & $25.2 \pm 21.0$ & $<.001$ & $25.8 \pm 19.3(299)$ & .342 & .048 \\
\hline 12 week & $27.8 \pm 24.9(80)$ & $<.001$ & $24.7 \pm 21.0$ & $<.001$ & .001 \\
\hline 6 month & $24.0 \pm 22.8(64)$ & $<.001$ & $37.0 \pm 87.8(132)$ & .483 & .495 \\
\hline 1 year & $23.3 \pm 24.6(45)$ & $<.001$ & $24.1 \pm 18.7(81)$ & $<.001$ & .357 \\
\hline \multicolumn{6}{|l|}{ SF-12 PCS } \\
\hline Preoperative & $30.2 \pm 7.3(99)$ & & $31.5 \pm 8.5(222)$ & & .025 \\
\hline 6 week & $37.6 \pm 10.6(99)$ & $<.001$ & $38.2 \pm 10.6(222)$ & $<.001$ & .096 \\
\hline 12 week & $39.9 \pm 11.3(63)$ & $<.001$ & $40.5 \pm 12.0$ & $<.001$ & .303 \\
\hline 6 month & $40.9 \pm 11.7(56)$ & $<.001$ & $39.0 \pm 12.2(110)$ & $<.001$ & .490 \\
\hline 1 year & $43.3 \pm 13.0(48)$ & $<.001$ & $40.7 \pm 12.2(93)$ & $<.001$ & .159 \\
\hline \multicolumn{6}{|l|}{ PROMIS PF } \\
\hline Preoperative & $35.9 \pm 6.2(75)$ & & $36.5 \pm 7.7(162)$ & & .095 \\
\hline 6 week & $41.9 \pm 8.0(75)$ & $<.001$ & $42.6 \pm 8.8(162)$ & $<.001$ & .460 \\
\hline 12 week & $43.9 \pm 7.9(47)$ & $<.001$ & $45.3 \pm 10.2(104)$ & $<.001$ & .272 \\
\hline 6 month & $44.6 \pm 9.1(41)$ & $<.001$ & $42.6 \pm 10.3(89)$ & $<.001$ & .284 \\
\hline 1 year & $44.8 \pm 8.9(35)$ & $<.001$ & $45.4 \pm 12.1(66)$ & $<.001$ & .839 \\
\hline
\end{tabular}

Abbreviations: ODI, Oswestry Disability Index; PROMIS PF, Patient-Reported Outcomes Measurement Information System Physical Function; SD, standard deviation; SF-12 PCS, 12-item short form physical composite score; VAS, visual analog scale.

${ }^{\text {a }} P$ value was calculated using the paired $t$ test (continuous) to compare each time point score with the preoperative value.

${ }^{\mathrm{b}} P$ value was calculated using the Student $t$ test (continuous) to compare each time point among subgroups.

A bolded $\mathrm{P}$ value $(<0.05)$ indicates a statistically significant difference between the two groups being compared.

Table 4. Achievement of minimal clinically important difference (MCID), percentage ( $n /$ total).

\begin{tabular}{|c|c|c|c|c|c|}
\hline PRO & Preop to $6 \mathrm{wk}$ & Preop to 3 mo & Preop to $6 \mathrm{mo}$ & Preop to $12 \mathrm{mo}$ & Overall met MCID \\
\hline \multicolumn{6}{|l|}{ VAS back } \\
\hline Female & $70.1(279 / 398)$ & $78.6(313 / 398)$ & $83.9(334 / 398)$ & $91.2(363 / 398)$ & $97.5(388 / 398)$ \\
\hline Male & $70.7(123 / 174)$ & $83.9(146 / 174)$ & $86.2(150 / 174)$ & $88.5(154 / 174)$ & $97.1(169 / 174)$ \\
\hline$P$ value & .887 & .146 & .485 & .314 & .804 \\
\hline \multicolumn{6}{|l|}{ VAS leg } \\
\hline Female & $49.8(198 / 398)$ & $70.6(281 / 398)$ & $76.1(303 / 398)$ & $85.4(340 / 398)$ & $94.5(376 / 398)$ \\
\hline Male & $51.7(90 / 174)$ & $67.8(118 / 174)$ & $79.3(138 / 174)$ & $86.2(150 / 174)$ & $93.7(163 / 174)$ \\
\hline$P$ value & .664 & .504 & .405 & .807 & .708 \\
\hline \multicolumn{6}{|l|}{ ODI } \\
\hline Female & $73.4(292 / 398)$ & $84.2(335 / 398)$ & $85.2(339 / 398)$ & $93.5(372 / 398)$ & $98.2(391 / 398)$ \\
\hline Male & $79.3(138 / 174)$ & $85.1(148 / 174)$ & $93.1(162 / 174)$ & $92.5(161 / 174)$ & $96.6(168 / 174)$ \\
\hline$P$ value & .130 & .788 & .008 & .682 & .212 \\
\hline \multicolumn{6}{|l|}{ SF-12 } \\
\hline Female & $54.3(216 / 398)$ & $73.6(293 / 398)$ & $76.6(305 / 398)$ & $79.4(316 / 398)$ & $94.2(375 / 398)$ \\
\hline Male & $51.2(89 / 174)$ & $66.6(116 / 174)$ & $70.7(123 / 174)$ & $75.3(131 / 174)$ & $92.0(160 / 174)$ \\
\hline$P$ value & .491 & .090 & .132 & .274 & .311 \\
\hline \multicolumn{6}{|l|}{ PROMIS } \\
\hline Female & $62.1(247 / 398)$ & $74.6(297 / 398)$ & $74.6(297 / 398)$ & $84.9(338 / 398)$ & $95.5(380 / 398)$ \\
\hline Male & $60.3(105 / 174)$ & $74.1(129 / 174)$ & $74.1(129 / 174)$ & $81.0(141 / 174)$ & $90.8(158 / 174)$ \\
\hline$P$ value & .698 & .903 & .577 & .246 & .030 \\
\hline
\end{tabular}

Abbreviations: ODI, Oswestry Disability Index; PRO, patient-reported outcome; PROMIS, Patient-Reported Outcomes Measurement Information System; SF-12, 12item short form score; VAS, visual analog scale.

A bolded $\mathrm{P}$ value $(<0.05)$ indicates a statistically significant difference between the two groups being compared. Other bolded percentage values are associated with the statistically significant $\mathrm{P}$ value. 
significant difference in the proportion of patients who achieved MCID among sexes for the disability metric ODI $(P=.008)$.

\section{DISCUSSION}

Understanding the effect of demographic factors on outcomes following spine surgery has become critical and can enable surgeons to better counsel patients and guide expectations. The relationship between sex and perioperative outcomes has remained debated. The present study sought to discern the true clinical relationship between sex and PROMs for patients undergoing decompression surgery of the lumbar spine. Our cohort had a larger proportion of male patients $(69.6 \%)$. Patients were generally young and otherwise healthy, with a mean age of 46.8 years and with $86.6 \%$ holding an American Society of Anesthesiology score of 2 or less. The cohort of female patients had a smaller proportion of active tobacco users and a higher prevalence of arthritis, with no additional demographic differences between the two groups. Regarding symptomatology, the female cohort reported worse preoperative leg pain, disability, and overall physical function (via SF-12) relative to men. However, the only significant differences in postoperative absolute outcome measures were ODI scores at 6 and 12 weeks and VAS back and leg scores at 6 months, with the differences disappearing by the 6-month and 1-year follow-up mark, respectively. Women had a lower likelihood of meeting the MCID for ODI at 6 months, but were equally likely to achieve this MCID at final followup. Moreover, there were no differences in the likelihood of achieving the MCID at 1 year postoperative for the five patient-reported outcomes that were recorded and analyzed.

These findings are consistent with previous research of patients undergoing lumbar decompression surgery. The predominance of male patients has been exhibited in similar studies ${ }^{4,21}$ and may be attributable to the greater degree of disc degeneration than in age-matched women ${ }^{9}$ or to sex-specific behaviors and referral patterns. Patients did generally well in response to surgery, with improvements in absolute PROMs that were similar to prior efforts, including the highly cited Spine Patient Outcomes Research Trials. ${ }^{4,5}$ Finally, the mean duration of surgery and length of stay were consistent with an experienced surgeon performing a standard minimally invasive decompressive surgi- cal technique. ${ }^{22,23}$ These similarities to previous efforts support the generalizability of our findings.

There has been a limited effort to date to elucidate the relationship between sex and perioperative outcomes following lumbar decompression surgery. Strömqvist et al performed an analysis of 11237 patients in the Swedish National Spine Surgical Register who underwent lumbar decompression surgery with a primary objective of comparing outcomes between men and women. ${ }^{16}$ Similar to the present study, they found no significant difference in the degree of absolute improvement in PROMs. Despite this, women did report significantly worse pre- and postoperative absolute PROM values. The reasons for this discrepancy are unclear, but the authors suggest it may be related to sex-specific delays in presentation or a willingness to attempt longer courses of nonoperative care. ${ }^{17}$ Similarly, Gulati et al retrospectively reviewed 3245 patients in the Norwegian Registry for Spine Surgery who had undergone single-level lumbar decompressions. ${ }^{15}$ Although their primary objective was to determine differences between the adult and adolescent population, they found that female sex was an independent risk factor for less improvement in ODI at 1 year postoperative (parameter estimate $-1.8,95 \%$ confidence interval $[\mathrm{CI}]-3.1$ to $-0.4, P=.010)$. Despite the statistical findings of the aforementioned studies, the clinical significance of sex on perioperative outcomes for lumbar decompression surgery has remained unclear.

Several groups have examined the role of sex on the likelihood of achieving an MCID in PROM following lumbar spine surgery. Siccoli et al, for example, analyzed 3279 patients undergoing a variety of surgical procedures for degenerative pathology of the lumbar spine, including discectomy, laminectomy, or fusion, for differences in outcome measures between sexes. ${ }^{12}$ Similar to the present study, they found that women had a higher degree of functional disability (via ODI score) at 6 weeks and at 12 and 24 months after surgery than men. However, the team also reported that men and women had no difference in the likelihood of experiencing "clinical success", which was defined as achieving a minimum of $30 \%$ improvement in ODI from baseline to follow-up (82\% of men and $79 \%$ of women; $P=.34$ ). The likelihood of achieving MCID in any additional measures was not examined. Similarly, Triebel et al performed a 
retrospective review of 2251 men and 2521 women in the Swedish National Spine Register who had undergone lumbar fusion for degenerative disc disease and chronic low back pain. ${ }^{14}$ Consistent with our findings, they too found that women reported more severe symptoms preoperatively. However, they reported that female sex was associated with an increased likelihood of achieving MCID in leg pain (odds ratio $=1.39,95 \%$ CI 1.19 $1.61, P<.01$ ), back pain (odds ratio $=1.20,95 \% \mathrm{CI}$ $1.03-1.40, P=.02$ ), and disability scores (odds ratio $=1.24,95 \%$ CI $1.05-1.47, P=.01)$. Although these studies have further contributed to our understanding of this complex area, the effect of sex on achieving MCID for lumbar decompression surgery has yet to be publicized.

Despite a similar degree of improvement in response to surgery, the reasons for differences in absolute value of outcome measures between sexes remain debated. There have been multiple attempts at explaining sex-related differences in pain perception with no clear consensus. ${ }^{24,25}$ This is not isolated to the postoperative state, as the female cohort in the present study reported worse preoperative symptoms compared with men, including the degree of leg pain, disability, and overall function. These findings are consistent with those of Strömqvist et al who first found that women were likely to report worse symptoms before lumbar decompression surgery. ${ }^{17}$ This could be attributable to an advanced stage of the disease in females at the time of intervention, a finding that has been supported for degenerative arthritis and other subspecialties of orthopedic surgery. ${ }^{26}$ There may also be underlying physiological and hormonal differences in pain perception, but these remain poorly understood. ${ }^{24,25}$ Lastly, differences in inflammatory pathways and the relative effectiveness of analgesics may play an important role. $^{27}$ Further research is necessary to grasp the multifactorial nature of this topic.

The results of the present study should be considered within the context of some notable limitations. The minimum clinical follow-up necessary for inclusion was 12 months, and this was also the final time point for analysis of MCID achievement. Previous research has suggested that female patients may experience a drawn out recovery process for radicular and neurogenic claudication symptoms in response to both surgical and nonsurgical care. ${ }^{28}$ Although 12 months has been suggested to be a sufficient duration to assess the true clinical benefit following lumbar decompression surgery, ${ }^{29}$ it is possible that female patients may experience even more clinical improvement between 12 and 24 months relative to their male counterparts. Triebel et al, for example, found that women experienced a slower recovery and a higher likelihood for achieving MCID than the male cohort but required a 2year follow-up to appreciate this effect. ${ }^{14}$ In addition, the duration of preoperative symptoms was not known or analyzed. This may be a contributing factor to the generally worse preoperative pain, disability, and physical function scores for the female cohort that was not captured within our statistical analysis. Therefore, future prospective analysis may be beneficial.

\section{CONCLUSION}

The relationship between sex and perioperative outcomes remains debated. This is the first study to analyze the role of sex on the achievement of MCID in response to lumbar decompression surgery alone. We found that, although women may present with worse preoperative symptoms, there is no difference in the overall likelihood of achieving the MCID of five of the most commonly used PROMs (VAS back/leg, ODI, SF-12, PROMIS) in spine research today. Surgeons may use this information to appropriately counsel patients and guide expectations following surgical intervention.

\section{REFERENCES}

1. Vogt MT, Cawthon PM, Kang JD, Donaldson WF, Cauley JA, Nevitt MC. Prevalence of symptoms of cervical and lumbar stenosis among participants in the Osteoporotic Fractures in Men Study. Spine (Phila Pa 1976). 2006;31(13):14451451. doi:10.1097/01.brs.0000219875.19688.a6

2. Hicks GE, Morone N, Weiner DK. Degenerative lumbar disc and facet disease in older adults: prevalence and clinical correlates. Spine (Phila Pa 1976). 2009;34(12):1301. doi:10. 1097/BRS.0b013e3181a18263

3. Kalichman L, Cole R, Kim DH, et al. Spinal stenosis prevalence and association with symptoms: the Framingham Study. Spine J. 2009;9(7):545-550. doi:10.1016/j.spinee.2009.03. 005

4. Weinstein JN, Tosteson TD, Lurie JD, et al. Surgical vs nonoperative treatment for lumbar disk herniation: the Spine Patient Outcomes Research Trial (SPORT): a randomized trial. JAMA. 2006;296(20):2441-2450. doi:10.1001/jama.296.20.2441

5. Weinstein JN, Tosteson TD, Lurie JD, et al. Surgical versus nonsurgical therapy for lumbar spinal stenosis. $N$ Engl $J$ Med. 2008;358(8):794-810. doi:10.1056/NEJMoa0707136

6. Deyo RA, Mirza SK, Martin BI. Error in trends, major medical complications, and charges associated with surgery for 
lumbar spinal stenosis in older adults. JAMA. 2011;306(10):1088. doi:10.1001/jama.2011.1300

7. Glassman SD, Carreon LY, Dimar JR, Campbell MJ, Puno RM, Johnson JR. Clinical outcomes in older patients after posterolateral lumbar fusion. Spine J. 2007;7(5):547-551. doi:10.1016/j.spinee.2006.11.003

8. Schoenfeld AJ, Sieg RN, Li G, Bader JO, Belmont PJ Jr, Bono CM. Outcomes after spine surgery among racial/ethnic minorities: a meta-analysis of the literature. Spine $J$. 2011;11(5):381-388. doi:10.1016/j.spinee.2011.03.013

9. Miller JA, Schmatz C, Schultz AB. Lumbar disc degeneration: correlation with age, sex, and spine level in 600 autopsy specimens. Spine (Phila Pa 1976). 1988;13(2):173-178.

10. Shabat S, Folman Y, Arinzon Z, Adunsky A, Catz A, Gepstein R. Gender differences as an influence on patients' satisfaction rates in spinal surgery of elderly patients. Eur Spine J. 2005;14(10):1027-1032. doi:10.1007/s00586-004-0808-Z

11. Pochon L, Kleinstück FS, Porchet F, Mannion AF. Influence of gender on patient-oriented outcomes in spine surgery. Eur Spine J. 2016;25(1):235-246. doi:10.1007/s00586015-4062-3

12. Siccoli A, Staartjes VE, de Wispelaere MP, Schröder ML. Gender differences in degenerative spine surgery: do female patients really fare worse? Eur Spine J. 2018;27(10):2427-2435. doi:10.1007/s00586-018-5737-3

13. Elsamadicy AA, Reddy GB, Nayar G, et al. Impact of gender disparities on short-term and long-term patient reported outcomes and satisfaction measures after elective lumbar spine surgery: a single institutional study of 384 patients. World Neurosurg. 2017;107:952-958. doi:10.1016/j.wneu.2017.07.082

14. Triebel J, Snellman G, Sandén B, Strömqvist F, Robinson Y. Women do not fare worse than men after lumbar fusion surgery: two-year follow-up results from 4,780 prospectively collected patients in the Swedish National Spine Register with lumbar degenerative disc disease and chronic low back pain. Spine J. 2017;17(5):656-662. doi:10.1016/j.spinee.2016.11. 001

15. Gulati S, Madsbu MA, Solberg TK, et al. Lumbar microdiscectomy for sciatica in adolescents: a multicentre observational registry-based study. Acta Neurochir (Wien). 2017;159(3):509-516. doi:10.1007/s00701-017-3077-4

16. Strömqvist F, Strömqvist B, Jönsson B, Karlsson MK. Inferior outcome of lumbar disc surgery in women due to inferior preoperative status: a prospective study in 11,237 patients. Spine (Phila Pa 1976). 2016;41(15):1247-1252. doi:10. 1097/BRS.0000000000001492

17. Strömqvist F, Strömqvist B, Jönsson B, Karlsson MK. Gender differences in patients scheduled for lumbar disc herniation surgery: a National Register Study including 15,631 operations. Eur Spine J. 2016;25(1):162-167. doi:10. 1007/s00586-015-4052-5

18. McCormick JD, Werner BC, Shimer AL. Patientreported outcome measures in spine surgery. J Am Acad Orthop Surg. 2013;21(2):99-107. doi:10.5435/JAAOS-21-02-99

19. Parker SL, Mendenhall SK, Shau DN, et al. Minimum clinically important difference in pain, disability, and quality of life after neural decompression and fusion for same-level recurrent lumbar stenosis: understanding clinical versus statistical significance. J Neurosurg Spine. 2012;16(5):471-478. doi:10.3171/2012.1.SPINE11842

20. Steinhaus ME, Iyer S, Lovecchio F, et al. Minimal clinically important difference and substantial clinical benefit using PROMIS CAT in cervical spine surgery. Clin Spine Surg. 2019;32(9):392-397. doi:10.1097/BSD.0000000000000895

21. Weber H. Lumbar disc herniation. A controlled, prospective study with ten years of observation. Spine (Phila Pa 1976). 1983;8(2):131-140.

22. Rouben D, Casnellie M, Ferguson M. Long-term durability of minimal invasive posterior transforaminal lumbar interbody fusion: a clinical and radiographic follow-up. $J$ Spinal Disord Tech. 2011;24(5):288-296. doi:10.1097/BSD. 0b013e3181f9a60a

23. Mannion RJ, Guilfoyle MR, Efendy J, Nowitzke AM, Laing RJ, Wood MJ. Minimally invasive lumbar decompression: long-term outcome, morbidity, and the learning curve from the first 50 cases. J Spinal Disord Tech. 2012;25(1):47-51. doi:10.1097/BSD.0b013e31820baale

24. Racine M, Tousignant-Laflamme Y, Kloda LA, Dion D, Dupuis G, Choinière M. A systematic literature review of 10 years of research on sex/gender and experimental pain perception - part 1: are there really differences between women and men? Pain. 2012;153(3):602-618. doi:10.1016/j.pain.2011. 11.025

25. Racine M, Tousignant-Laflamme Y, Kloda LA, Dion D, Dupuis G, Choinière M. A systematic literature review of 10 years of research on sex/gender and pain perception - part 2: do biopsychosocial factors alter pain sensitivity differently in women and men? Pain. 2012;153(3):619-635. doi:10.1016/j. pain.2011.11.026

26. Katz JN, Wright EA, Guadagnoli E, Liang $\mathrm{MH}$, Karlson EW, Cleary PD. Differences between men and women undergoing major orthopedic surgery for degenerative arthritis. Arthritis Rheum. 1994;37(5):687-694. doi:10.1002/art. 1780370512

27. Kim H-J, Suh B-G, Lee D-B, et al. Gender difference of symptom severity in lumbar spinal stenosis: role of pain sensitivity. Pain Physician. 2013;16(6):E715-E723.

28. Peul WC, Brand R, Thomeer RTWM, Koes BW. Influence of gender and other prognostic factors on outcome of sciatica. Pain. 2008;138(1):180-191. doi:10.1016/j.pain.2007.12. 014

29. Staartjes VE, Siccoli A, de Wispelaere MP, Schröder ML. Patient-reported outcomes unbiased by length of followup after lumbar degenerative spine surgery: do we need 2 years of follow-up? Spine J. 2019;19(4):637-644. doi:10.1016/j.spinee. 2018.10.004

\section{Disclosures and COI: None.}

Corresponding Author: Kern Singh, MD, Department of Orthopaedic Surgery, Rush University Medical Center, 1611 W. Harrison St, Suite 300, Chicago, IL 60612. Phone: (312)-432-2373; Fax: (708)-409-5179; E-mail: kern.singh@rushortho. com.

Published 19 August 2021

This manuscript is generously published free of charge by ISASS, the International Society for the Advancement of Spine Surgery. Copyright (C 2021 ISASS. To see more or order reprints or permissions, see http://ijssurgery.com. 